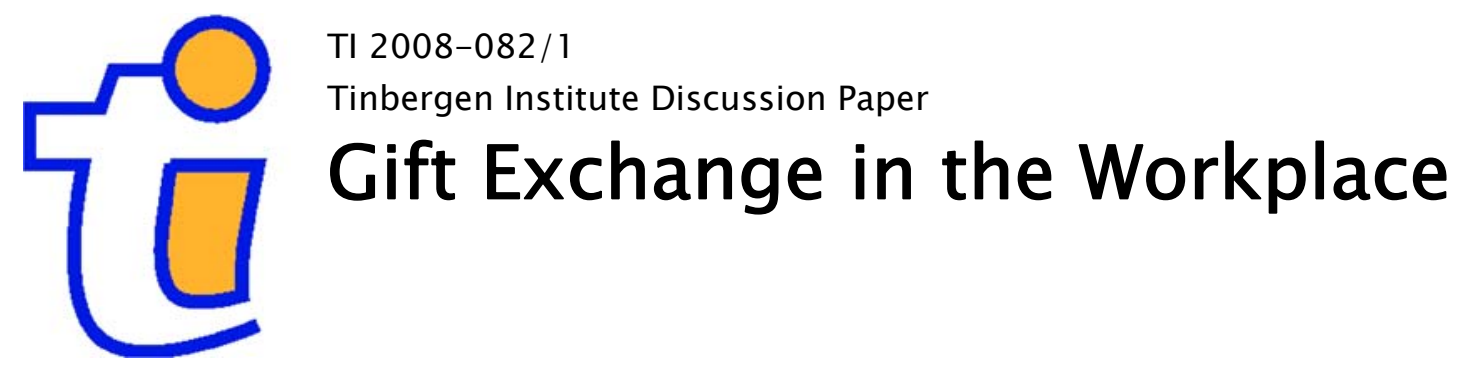

Robert Dur

Department of Economics, Erasmus University Rotterdam, Tinbergen Institute, and CESifo. 


\section{Tinbergen Institute}

The Tinbergen Institute is the institute for economic research of the Erasmus Universiteit Rotterdam, Universiteit van Amsterdam, and Vrije Universiteit Amsterdam.

Tinbergen Institute Amsterdam

Roetersstraat 31

1018 WB Amsterdam

The Netherlands

Tel.: +31(0)205513500

Fax: $+31(0) 205513555$

Tinbergen Institute Rotterdam

Burg. Oudlaan 50

3062 PA Rotterdam

The Netherlands

Tel.: + $31(0) 104088900$

Fax: $+31(0) 104089031$

Most TI discussion papers can be downloaded at http://www.tinbergen.nl. 


\title{
Gift Exchange in the Workplace: Money or Attention?*
}

\author{
Robert Dur ${ }^{\dagger}$
}

November 12, 2008

\begin{abstract}
We develop a model of manager-employee relationships where employees care more for their manager when they are more convinced that their manager cares for them. Managers can signal their altruistic feelings towards their employees in two ways: by offering a generous wage and by giving attention. Contrary to the traditional gift-exchange hypothesis, we show that altruistic managers may offer lower wages and nevertheless build up better social-exchange relationships with their employees than egoistic managers do. In such equilibria, a low wage signals to employees that the manager has something else to offer namely, a lot of attention - which will induce the employee to stay at the firm and work hard. Our predictions are well in line with some recent empirical findings about gift exchange in the field.
\end{abstract}

Keywords: manager-employee relationships, wages, extra-role behavior, sabotage, gift exchange, social exchange, conditional altruism, reciprocity, signaling game.

JEL-codes: D86, J41, M50, M54, M55

\footnotetext{
*Prepared for the invited session "Organizational Economics" at the 2008 Annual Congress of the European Economic Association in Milan. I thank two anonymous referees, Benoît Crutzen, Josse Delfgaauw, Vladimir Karamychev, Michael Kosfeld, Arjan Non, Hein Roelfsema, Joeri Sol, Ferdinand Von Siemens, and Christian Zehnder for detailed comments and stimulating discussions.

${ }^{\dagger}$ Department of Economics, Erasmus University Rotterdam, Tinbergen Institute, CESifo, and IZA. Address: Erasmus University, FEW/H 8-15, P.O. Box 1738, 3000 DR Rotterdam, The Netherlands. E-mail: dur@few.eur.nl
} 


\section{Introduction}

For many employees, it matters a great deal whether their manager genuinely cares about them as a person or sees them only as a means to an end. Data from Gallup surveys among a large number of employees and managers show that employees who feel that their supervisor cares about them as a person are more satisfied with their job, are less likely to quit, and are better motivated to work hard (Wagner and Harter 2006). Numerous studies in organizational psychology and management have reported similar patterns: When managers show that they care for their employees, social-exchange relationships develop, which engender effective work behavior, positive employee attitudes, and organizational commitment (see, e.g., the reviews by Rhoades and Eisenberger 2002; Cropanzano and Mitchell 2005).

These findings have a clear managerial implication, which can be found in many popular business books: Managers should build up good personal relationships with their employees and show that they genuinely care about them as persons. This, however, is often much easier said than done, for at least two reasons. First, caring genuinely about an employee is usually not so much a matter of choice, but rather a matter of the personality of the manager, the personality fit between the manager and his employee, and other factors over which the manager has only limited control. Second, even if a manager truly cares for his employee, he may not always find ways to credibly signal this, particularly when managers who actually do not care can pretend that they do. An important issue therefore is: How can caring managers credibly signal their true feelings to their employees?

The economics literature on manager-worker relationships has so far focused on the role of wages in engendering employees' sentiments towards their manager. The famous gift-exchange hypothesis posits that workers who are paid higher than market-clearing wages develop sentiment for their employer and reciprocate the 'gift' by working harder (Akerlof 1982). Arbak and Kranich (2007) and Ellingsen and Johannesson (2008) have recently provided microfoundations for this hypothesis by developing models where altruistic managers signal their feelings by offering higher wages than ego- 
istic managers. Studies in management and organizational psychology have considered a much broader set of managerial tools facilitating relationshipbuilding between managers and employees, falling into two broad categories: economic resources and socioemotional resources. Economic resources address "financial needs and tend to be tangible" whereas socioemotional resources address "social and esteem needs (and are often symbolic and particularistic)." (Cropanzano and Mitchell 2005, p. 881)

This paper provides a game-theoretic analysis of managers' use of these two instruments in building up social-exchange relationships with their employees. We develop a signaling model in the spirit of Levine (1998), where managers differ in innate altruism towards their employees and employees are conditionally altruistic towards their manager. That is, employees care more for their manager (or are less spiteful) when they are more convinced that their manager genuinely cares about them. Employees form rational beliefs about their managers' care by observing the wage they offer and the socioemotional resources that they give (which we call 'attention'). Our key result is that, in any separating equilibrium, altruistic managers always give more attention than egoistic managers, but need not pay higher wages. Contrary to the traditional gift-exchange hypothesis, we show that altruistic managers may offer lower wages and nevertheless build up better social-exchange relationships with their employees than egoistic managers do. In such equilibria, low wages signal to employees that the manager has something else to offer - namely, high socioemotional resources - which will induce the employee to stay at the firm and work hard.

Our analysis offers an explanation for the disparity between the results of experimental studies on gift-exchange in the lab and those in the field. Starting with Fehr, Kirchsteiger, and Riedl (1993), numerous laboratory experiments have provided evidence supporting the traditional gift-exchange hypothesis (see Fehr and Gächter 2000 for an overview). Recent field experiments, however, find little or no effect of paying generous wages on worker's productivity (e.g., Gneezy and List 2006; Hennig-Schmidt, Rockenbach, and Sadrieh 2008). Our theoretical analysis suggests that we should not dismiss the relevance of gift-exchange in the field on the basis of these findings, 
but rather adopt a broader view on how exchange relationships are formed. While participants of lab experiments commonly engage in anonymous interactions with money as the only medium of exchange, managers in naturally occurring workplaces have, in addition to wages, socioemotional tools at their disposal to build up exchange relationships with their workers. Our results suggest that application of these tools is often preferred to paying generous wages and that better manager-worker relationships may go hand in hand with lower wages. A high wage offer may therefore be interpreted quite differently in the field than in the lab. Our prediction that symbolic gifts (such as good personal contact) rather than wages are manager's main means of exchange in the field is also well in line with survey evidence by Campbell and Kamlani (1997) and Bewley (1999) on the determinants of worker's morale, as well as with empirical work showing that firms with bad management-worker relationships are penalized in that they need to pay higher wages to attract and retain workers (e.g., Borzaga and Depedri 2005). Lastly, a recent field experiment complemented by a questionnaire study by Kube, Maréchal, and Puppe (2008) finds that a gift-in-kind is significantly more likely to signal kind intentions than a wage increase, and in contrast to a wage increase - significantly increases worker's productivity.

The paper is organized as follows. The following section describes the model. Section 3 presents the main results. Section 4 concludes.

\section{The Model}

Consider an economy with two types of managers: altruistic and egoistic. Altruistic managers care about their profits and about the well-being of the employees that they hire; egoistic managers care only about profits. Importantly, while each manager knows his own preferences, an employee cannot directly observe his manager's type; employees can only infer a manager's type from his actions.

Each manager hires one employee from a sufficiently large pool and takes two actions: he offers a flat-wage contract and, if the employee has accepted the contract, he gives attention to his employee. Attention is non- 
contractible and includes all kinds of manager's actions which are valuable to the employee, costly to the manager, and not directly related to productive tasks. Examples of such actions from the business literature are showing interest in the employee's personal life, listening to personal problems, paying respect, and so on. The value of attention to the employee is described by the strictly increasing and concave function $g(a)$ with $g(0)=0$. The manager's cost of giving attention is given by $f(a)$, which is increasing and convex in attention $a$. Further, we assume that $f(0)=f_{a}(0)=0$, where (throughout the paper) subscripts denote partial derivatives.

After receiving the manager's attention, the employee has an option to quit, resulting in outside option direct utility $\bar{U} \geq 0$ for the employee. Quitting implies that the manager is left without any revenues from production, but need not pay the wage $w{ }^{1}$ If the employee stays, he exerts effort $e$, which is non-contractible. We allow $e$ to be positive and negative, where positive $e$ represents extra-role behavior benefiting the manager, while negative $e$ represents sabotage activities damaging the manager. Effort affects the manager's payoff as described by the strictly increasing function $q(e)$, which is convex for $e<0$ and concave for $e>0$. Further, we assume that $q(0)>0$; that is, an employee who abstains from extra-role behavior as well as from sabotage yields positive revenues to the manager. Both positive and negative $e$ come at a cost to the employee, described by the strictly convex function $c(e)$, with $c(0)=c_{e}(0)=0$.

While managers differ in type, employees are identical. Employees are conditionally altruistic: An employee is more altruistic (or less spiteful) towards his manager when he is more convinced that his manager is altruistic towards him. Hence, when a manager's wage offer and attention make that employees hold more optimistic beliefs about the manager's altruism, em-

\footnotetext{
${ }^{1}$ Alternatively, we could assume that if the employee quits, he receives $\beta w, 0<\beta<1$, and enjoys outside option utility $(1-\beta) \bar{U}$, where $\beta$ measures the time elapsed between hiring and quitting. This does not affect any of the main results. As we shall see, the employee's option to quit implies that the manager's attention may not only affect work effort but also turnover. If employees would not have an option to quit, separating equilibria can arise in which, after receiving attention, employees working for an egoistic manager actually regret taking the job, but cannot resign.
} 
ployees' altruism towards the manager increases.

Summarizing, the manager's payoff (given that the employee stays) is:

$$
\pi=q(e)-w-f(a)+\alpha[w-c(e)+g(a)],
$$

where egoistic managers have $\alpha=0$, altruistic managers have $\alpha=\widetilde{\alpha}$, and $0<\widetilde{\alpha}<1$. The employee's expected utility is:

$$
E(U)=E\{w-c(e)+g(a)+\gamma(\alpha)[q(e)-w-f(a)]\},
$$

where $E$ is the expectation operator, $-1<\gamma(\alpha)<1$ measures the employee's altruism or spite towards a manager with altruism $\alpha$, and our assumption of conditional altruism implies that $\gamma^{\prime}(\alpha)>0 .{ }^{2}$ The timing of the game is as follows:

1. The manager offers a flat wage contract.

2. If the contract is accepted, the manager gives attention.

3. The employee decides whether to stay and exert effort or quit and enjoy his outside option utility.

4. Payoffs are realized.

The employee only accepts the contract offered at the beginning of the game when his expected utility exceeds his outside option utility: $E(U) \geq \bar{U}$. As to the managers' outside option, we assume that both altruistic and egoistic managers always find it optimal to hire an employee.

We focus throughout on the 'best separating equilibrium' in pure strategies; that is, we characterize the equilibrium where altruistic managers

\footnotetext{
${ }^{2}$ Note that the specification of (1) and (2) follows Levine (1998) in that an altruistic person does not enjoy an other person's utility from being altruistic. This avoids some complexities, but does not affect the main results. Gul and Pesendorfer (2007) have recently developed a more general model of interdependent preferences, of which Levine's (1998) reciprocity model is a special case. Their two main theorems offer an interpretation of behavioral types as hierarchies of preference responses. Other closely related papers include Rotemberg (2008), who studies a model where agent's altruism depends nonlinearly on his perception of the altruism of the person he is interacting with, and Andreoni and Bernheim (2008), who develop a model where people like to be perceived as fair. The latter paper also provides experimental evidence for the model's main predictions.
} 
through their choice of wage and attention reveal themselves in a way that brings them highest payoff. ${ }^{3}$ Clearly, a separating equilibrium in pure strategies may not always exist. For instance, when there are relatively many altruistic managers in the economy and employee's responsiveness to manager's type $\left(\gamma^{\prime}(\alpha)\right)$ is low, altruistic managers have little or no incentive to signal their type. Since the aim of our study is to learn how managers may optimally reveal themselves, we shall focus on situations where the payoff from doing so is sufficiently high. For brevity, we do not discuss hybrid equilibria where egoistic managers play mixed strategies.

\section{Equilibrium Behavior}

We solve for a Perfect Bayesian Equilibrium by backward induction, and so start with the last stage of the game: the employee's effort choice. In a separating equilibrium, the employee's belief about his manager's type at the last stage of the game corresponds to the manager's true type, and so the first-order condition for optimal effort $e^{*}$ reads:

$$
-c_{e}\left(e^{*}\right)+\gamma(\alpha) q_{e}\left(e^{*}\right)=0
$$

Clearly, depending on whether $\gamma$ is positive or negative, the worker engages in extra-role behavior $\left(e^{*}>0\right)$ or sabotage $\left(e^{*}<0\right)$. It is also clear from (3) that, as a result of employee's conditional altruism, optimal effort $e^{*}$ strictly increases with the manager's altruism $\alpha$. In other words, better manager-worker relations improve workers' performance, as workers take more account of their managers' interest when choosing effort.

Next consider the employee's decision whether to quit. Comparing his expected utility of quitting and staying, it follows that the employee stays

\footnotetext{
${ }^{3}$ Inspection of (1) reveals that the single-crossing property is satisfied for both the wage and attention $\left(\pi_{w \alpha}=1>0 ; \pi_{a \alpha}=g_{a}>0\right)$, implying that both can potentially serve as signaling instrument. Note also that the separability of the wage and attention in the payoff functions implies that we need not worry about further signaling conditions that would be required in a more general set-up.
} 
if:

$$
w-c\left[e^{*}(\alpha)\right]+\gamma(\alpha)\left\{q\left[e^{*}(\alpha)\right]-w\right\} \geq \bar{U},
$$

where the direct benefits and costs of attention have dropped out as these are sunk at this stage. Clearly, an employee with neutral feelings towards his manager $(\gamma(\alpha)=0)$ stays if the wage compensates for foregoing the outside option and for his effort cost (which is zero in this case). Employees with warm feelings towards their manager $(\gamma(\alpha)>0)$ are willing to stay for a lower wage, while employees with hostile feelings $(\gamma(\alpha)<0)$ require a higher compensation, unless staying at the firm does more harm to the manager than quitting does. The latter case, however, is irrelevant in our context, because anticipating this behavior, a manager would not hire an employee in the first place. Hence, we can conclude that better manager-worker relations make it more easy to retain an employee.

The manager's choice of attention is somewhat more involved, as both altruistic and signaling motives may play a role. Let us first consider an egoistic manager. In a separating equilibrium, altruistic manager's decisions are such that an egoistic manager has no incentive to mimic. Hence, an egoistic manager's optimal attention solves the first-order condition:

$$
-f_{a}\left(a^{*}\right)+\alpha g_{a}\left(a^{*}\right)=0
$$

which follows from maximizing the manager's payoff (1) with respect to attention $a$, while noting that - given that managers reveal their type neither employee effort nor employee retainment depends on manager's attention (see (3) and (4)). Since egoistic managers do not care about their employees $(\alpha=0)$, condition (5) implies that they optimally give no attention $\left(a^{*}=0\right)$.

An altruistic manager's optimal attention depends on whether signaling motives are operative at the margin. There are two reasons for why signaling motives may not be operative in a separating equilibrium. First, altruistic managers may have already revealed their type through a sufficiently generous wage offer in the first stage of the game. Second, altruistic managers may care so much for their employees, that they optimally give more atten- 
tion than necessary to reveal their type. In either case, optimal attention is described by first-order condition (5) with $\alpha=\widetilde{\alpha}$; altruistic managers give a strictly positive level of attention $\left(a^{*}>0\right)$ because they enjoy making their employees happy. Note that attention falls short of the first-best because the manager cares more about himself than about the worker, $\widetilde{\alpha}<1 .{ }^{4}$ If, by contrast, signaling motives are operative at the margin, altruistic managers raise attention to a level $a^{* *}$ that is just sufficient to keep egoistic managers from mimicking. The revelation constraint reads:

$$
q\left[e^{*}(0)\right]-w(0) \geq q\left[e^{*}(\widetilde{\alpha})\right]-w(\widetilde{\alpha})-f\left(a^{* *}\right),
$$

where $w(\alpha)$ is the wage offered by a manager with altruism $\alpha$ and $e(\alpha)$ is employee's effort as described by (3). If $a^{* *}$ as defined by (6) exceeds $a^{*}(\widetilde{\alpha})>0$ as defined by (5), altruistic managers give $a^{* *}$; otherwise, they give $a^{*}(\widetilde{\alpha})$. Hence, altruistic managers always give more attention than egoistic managers, either for altruistic reasons or for signaling reasons.

Lastly, consider managers' wage offer in the first stage of the game. It is easy to verify that, in a separating equilibrium, the employee's ex ante participation constraint $(E(U) \geq \bar{U})$ is always redundant. The reason is simple: since a manager gives attention after the worker has signed the contract, but before the worker takes his quit decision, any net benefits from attention relax the participation constraint, but not the retainment constraint. Hence, if the retainment constraint is satisfied, so is the participation constraint. Since in a separating equilibrium egoistic managers do not mimic altruistic managers, they offer a wage that satisfies the retainment constraint (4) with equality. Altruistic managers face the following optimization problem:

$$
\max _{w} q(e)-w-f(a)+\alpha[w-c(e)+g(a)]
$$

subject to the retainment constraint (4) and the revelation constraint (6), and where attention is described by (6) if the revelation constraint binds

\footnotetext{
${ }^{4}$ It is easy to verify that if attention and effort are contractible, and manager's types are observable, managers reach first-best profits when the contract specifies attention and effort such that $g_{a}(a)-f_{a}(a)=0$ and $q_{e}(e)-c_{e}(e)=0$.
} 
$\left(a=a^{* *}\right)$ and by (5) if it does not $\left(a=a^{*}\right)$. The Kuhn-Tucker conditions to (7) imply that we need to distinguish three cases: 1) the retainment constraint binds, the revelation constraint does not; 2) both constraints bind; 3) the revelation constraint is the only binding constraint. ${ }^{5}$ Let us discuss these three cases in turn.

In the first case, signaling motives do not impact altruistic managers' choices. Hence, they give attention $a^{*}(\widetilde{\alpha})$ as described by first-order condition (5) and offer a wage that makes their employees just indifferent between staying and quitting, as described by (4). Clearly, since $\gamma(\widetilde{\alpha})>\gamma(0)$, it follows from (4) that altruistic managers pay a lower wage than egoistic managers do $(w(\widetilde{\alpha})<w(0))$. This is a compensating wage differential: As employees derive a nonpecuniary gain from working for a manager that truly cares for them, they are willing to take and keep the job even though it pays less than a job offered by an egoistic manager. Moreover, following (3), altruistic managers' employees work harder, resulting in higher revenues from production $\left(q\left[e^{*}(\widetilde{\alpha})\right]>q\left[e^{*}(0)\right]\right)$. Egoistic managers nevertheless do not mimic altruistic managers when these benefits do not compensate for the cost of giving attention $f\left[a^{*}(\widetilde{\alpha})\right]$. Note that these results square well with the empirical evidence discussed in the Introduction showing that better manager-worker relationships are associated with better work performance and lower wages.

In the second case, the revelation constraint binds so that altruistic managers must be more generous with salary and/or attention so as to signal their type. Obviously, they want to signal in the least costly way. The Kuhn-Tucker conditions yield a very simple solution: Altruistic managers always use attention as a signaling instrument, and only as a last resort increase the wage as well. The reason for this result is straightforward. In

\footnotetext{
${ }^{5}$ The case where neither of the constraints bind is ruled out by the Kuhn-Tucker conditions. However, when assuming concave utility from income and a sufficiently large difference in income between the manager and the employee, it may happen that altruistic managers optimally leave a rent to their employees even when the revelation constraint is not binding. Nevertheless, as the retainment constraint is less binding for altruistic managers, they may also in this case pay a lower wage than egoistic managers, and they always give higher attention.
} 
the absence of signaling motives, altruistic managers give attention up to the point where their marginal cost of attention equal their marginal benefit, see (5). Hence, the cost of increasing attention are zero at the margin. Since a wage increase comes at a cost $1-\widetilde{\alpha}>0$ to an altruistic manager (see (1)), attention is always used as a signaling instrument. As attention increases, the marginal net cost of attention increase as well and, at some point, increasing the wage becomes a better alternative. Attention and wage are equally cost-effective if: ${ }^{6}$

$$
\frac{f_{a}(a)}{f_{a}(a)-\widetilde{\alpha} g_{a}(a)}=\frac{1}{1-\widetilde{\alpha}} \Longrightarrow f_{a}(a)=g_{a}(a)
$$

that is, where attention reaches its first-best level. Hence, if revelation of type is still not achieved when $f_{a}(a)=g_{a}(a)$, altruistic managers do not increase attention any further, but instead increase the wage, implying that the retainment constraint becomes non-binding. Thus, we end up in the third case where the revelation constraint is the only binding constraint. In this third case, the wage offered by altruistic managers may become higher than the wage offered by egoistic managers; in the second case, altruistic managers always offer lower wages than egoistic managers. In either case, altruistic managers give more attention than egoistic managers.

\section{Concluding Remarks}

We have studied gift-exchange between managers and workers in a model where managers can signal their altruism towards their workers by offering high wages and by giving attention. Our analysis predicts a prominent role for attention and other socioemotional resources in gift-exchange relationships. Generous wages may complement these non-monetary gifts, but they

\footnotetext{
${ }^{6}$ This follows from differentiating (1) - implying that altruistic managers' net costs of increasing attention and of increasing the wage are $f_{a}(a)-\widetilde{\alpha} g_{a}(a)$ and $1-\widetilde{\alpha}>0$, respectively - and differentiating (6) - implying that the 'signaling benefits' of increasing attention and of increasing the wage are $f_{a}(a)$ and 1 , respectively. The Kuhn-Tucker conditions imply that managers optimally use the instrument(s) which achieve highest signaling benefits per unit net cost. Hence, managers are indifferent between the instruments when (8) holds.
} 
are used only when egoistic managers have strong incentives to mimic altruistic managers. When these incentives are moderate (e.g., because employee's responsiveness to manager's type is relatively low), altruistic managers pay lower wages than egoistic managers do, as employees derive a nonpecuniary gain from working for a manager who truly cares for them.

Our results depend crucially on the non-contractibility of manager's attention. If attention would be contractible, it is always set at the first-best level, and so wages are a more efficient signaling instrument than attention. However, when we make the additional assumption that altruistic managers are more efficient than egoistic managers in non-monetary gift-giving (as in Camerer 1988; Prendergast and Stole 2001; Ellingsen and Johannesson 2007), contractibility of attention does not change our results qualitatively. In that case, attention will always be used for signaling purposes, and the wage paid by managers who truly care for their employees may well be lower than the wage paid by narrowly self-interested managers.

The analysis can be extended in several other interesting directions, yielding new testable predictions. First, in addition to increasing employee's effort and reducing turnover, a manager's altruism can bring about other benefits (see Rotemberg 2006 for a survey). For instance, Rotemberg and Saloner (1993) show that, when contracts are incomplete, manager's altruism can improve incentives for employees to engage in innovation activities and thus can increase profits. Hence, in environments that are rich in innovation opportunities, the signaling activities studied in this paper may have a higher return and may thus be more prevalent than in environments with few innovation opportunities. Second, a manager's span of control may affect how fast his marginal cost of attention increase with attention. Following condition (8), this may imply that managers with a larger span of control are more likely to use wages on top of attention to signal their type. Likewise, the marginal value of manager's attention may decrease more rapidly for some workers than for others, and the inclination to reciprocate may differ among people, possibly depending on one's own kindness, as in the reciprocity model of Gul and Pesendorfer (2007). Lastly, a challenging issue is the sorting of people with different motivations into management and 
employee positions, and the matching of these types in equilibrium.

\section{References}

Akerlof, George A. (1982). "Labor Contracts as Partial Gift Exchange." Quarterly Journal of Economics, 97, 543-569.

Andreoni, James, and B. Douglas Bernheim (2008). "Social Image and the 50-50 Norm: A Theoretical and Experimental Analysis of Audience Effects." Mimeo, University of California, San Diego.

Arbak, Emrah, and Laurence Kranich (2007). "Can Wages Buy Loyalty?" Mimeo, Department of Economics, University at Albany, SUNY.

Bewley, Truman F. (1999). Why Wages Don't Fall during a Recesion. Harvard University Press.

Borzaga, Carlo, and Sara Depedri (2005). "Interpersonal Relations and Job Satisfaction: Some Empirical Results." In: Benedetto Gui and Robert Sugden, eds., Economics and Social Interaction; Accounting for Interpersonal Relations. Cambridge University Press.

Camerer, Colin (1988). "Gifts as Economic Signals and Social Symbols." American Journal of Sociology, 94, S180-S214.

Campbell, Carl M., and Kunal S. Kamlani (1997). "The Reasons for Wage Rigidity: Evidence from a Survey of Firms." Quarterly Journal of Economics, 112, 759-789.

Cropanzano, Russell, and Marie S. Mitchell (2005). "Social Exchange Theory: An Interdisciplinary Review." Journal of Management, 31, 874-900.

Ellingsen, Tore, and Magnus Johannesson (2007). "Generosity." Working paper, Stockholm School of Economics.

Ellingsen, Tore, and Magnus Johannesson (2008). "Pride and Prejudice: The Human Side of Incentive Theory." American Economic Review, 98, 9901008 .

Fehr, Ernst and Simon Gächter (2000). "Fairness and Retaliation: The Economics of Reciprocity." Journal of Economic Perspectives, 14, 159-181.

Fehr, Ernst, George Kirchsteiger, and Arno Riedl (1993). "Does Fairness Prevent Market Clearing? An Experimental Investigation." Quarterly 
Journal of Economics, 108, 437-459.

Gneezy, Uri, and John A. List (2006). "Putting Behavioral Economics to Work: Testing for Gift Exchange in Labor Markets Using Field Experiments." Econometrica, 74, 1365-1384.

Gul, Faruk, and Wolfgang Pesendorfer (2007). "The Canonical Space for Behavioral Types." Mimeo, Princeton University.

Hennig-Schmidt, Heike, Bettina Rockenbach, and Abdolkarim Sadrieh (2008). "In Search of Workers' Real Effort Reciprocity - A Field and a Laboratory Experiment." Journal of the European Economic Association, forthcoming.

Kube, Sebastian, Michel André Maréchal, and Clemens Puppe (2008). "The Currency of Reciprocity - Gift-Exchange in the Workplace." Working paper no. 377, Institute for Empirical Research in Economics, University of Zurich.

Levine, David K. (1998). "Modeling Altruism and Spitefulness in Experiments." Review of Economic Dynamics, 1, 593-622.

Prendergast, Canice, and Lars Stole (2001). "The Non-Monetary Nature of Gifts." European Economic Review, 45, 1793-1810.

Rhoades, Linda, and Robert Eisenberger (2002). "Perceived Organizational Support: A Review." Journal of Applied Psychology, 87, 698-714.

Rotemberg, Julio J. (2006). "Altruism, Reciprocity and Cooperation in the Workplace." In: Serge-Christophe Kolm and Jean Mercier Ythier, eds., Handbook of the Economics of Giving, Altruism and Reciprocity, Volume 2. Elsevier.

Rotemberg, Julio J. (2008). "Minimally Acceptable Altruism and the Ultimatum Game." Journal of Economic Behavior and Organization, 66, 457-476.

Rotemberg, Julio J., and Garth Saloner (1993). "Leadership Style and Incentives." Management Science, 39, 1299-1318.

Wagner, Rodd, and James K. Harter (2006). 12: The Elements of Great Managing, Gallup Press. 